\title{
TERRITÓRIO E POLÍTICAS DO TERRITÓRIO. A INTERPRETAÇÃO E A AÇÃO ${ }^{1}$
}

JosÉ REIS ${ }^{2}$

\section{INTRODUÇÃO}

Neste texto revisito dois mundos: o da interpretação e do conhecimento do território e o das formas de lidar com ele através das políticas públicas. Não podem ser, como é evidente, coisas desligadas. Pelo contrário, uma informa a outra e deviam moldar-se reciprocamente. Mas bem se sabe que não é assim que acontece na maior parte das vezes. Porventura, as políticas desligaram-se do território, privilegiando outras deliberações e outros propósitos, enquanto o território carecerá, cada vez mais, de um regresso interpretativo que lhe revalorize os fundamentos e a pertinência. É esta opção que tomo, supondo que há razões para isso. Discuto o que nos levou a formular interrogações sobre o território e procuro responder à pergunta "o que é o território?". Recuso que seja apenas uma questão de escala e acho que há uma epistemologia do território a construir, para podermos chegar a uma compreensão adequada do que dá valor à territorialidade. Assumo que as sociedades são estruturalmente polimórficas e nisso se manifestam as relações de poder que as constituem. As duas coisas devem ser centrais numa agenda territorialista.

Justamente porque é de poder que se trata, discuto por que razão há-de haver necessidade de formularmos políticas do território se as sociedades são, por natureza, espaciais. Por isso me parece que a "política-política" é que devia ser, ela própria, a sede da

Recebido: Março 2015. Aceite: Julho 2015.

1 Este texto é dedicado ao António Gama Mendes, com quem tanto aprendi. Não foi apenas o sentido da suavidade da vida, nas suas alegrias e amarguras, que aprendi com o António ao longo de 40 anos. Foi a vontade permanente de uma compreensão fina das coisas, uma compreensão sempre provisória, inquieta, à procura da mais sólida imaginação. Sei que um texto como este não resiste às suas perguntas, às suas dúvidas, à sua crítica virtuosa. Sei que, com ele, a percepção do território, uma percepção vivida, vista de muitos lados, é sempre mais exigente. Mas esta é a minha pequeníssima homenagem, do modo que eu sei, a um querido amigo, a um geógrafo ímpar, estimadíssimo por gerações e gerações de alunos, a um universitário que se deu todo o tempo para o ser plena e integralmente, a um homem culto sem fronteiras nem disciplinas. (Coimbra, 31 de dezembro de 2014).

2 José Reis é Professor catedrático da Faculdade de Economia da Universidade de Coimbra (FEUC) e Investigador do Centro de Estudos Sociais. Foi Presidente da Comissão de Coordenação da Região Centro, Secretário de Estado do Ensino Superior e Director da FEUC. Tem estudado o território e as instituições da economia. E-mail: jreis@fe.uc.pt 
territorialidade das políticas. Mas, porque assim não é na realidade, proponho uma taxonomia de políticas do território que acolham a proximidade, as densidades, a distância e o polimorfismo. Concluo desejando que toda a governação e todo o desenvolvimento fossem territoriais. Para que isso aconteça, ou na medida em que não acontece, faz sentido que mantenhamos uma agenda territorial capaz.

\section{ESPAÇO E TERRITÓRIO}

Defendi noutro lugar (Reis, 2013) que o desenvolvimento de perspectivas territorialistas na economia, da segunda metade do século XX para cá, resulta de um pressuposto - a importância da variável espaço no conhecimento -, de um objetivo - a busca de equidade socioeconómica - e de uma ambição interpretativa - a avaliação do papel dos territórios na formação das estruturas e das dinâmicas sociais contemporâneas.

De facto, as ciências sociais começaram por ignorar o território, não lhe dando lugar entre as variáveis necessárias à compreensão das realidades socioeconómicas. Depois, juntou-se a isso uma dimensão moral e ética, acrescentando um propósito de equidade, o qual se alcançaria através da ultrapassagem das assimetrias e das desigualdades sociais evidenciadas pelo simples uso, na análise, de uma variável espacial. Não tardou, porém, que um acréscimo de conhecimento marcasse também os estudos territorialistas: interessava aos especialistas saber qual era 'a razão de ser' do que acontecia em cada território. Tanto podia ser a mobilidade dos fatores de produção (as pessoas, os bens e os capitais deslocam-se no espaço) quanto a genealogia dos processos, visto que estes ocorrem em lugares, quer dizer, originam-se e desenvolvem-se em circunstâncias locais concretas, identificáveis e diferenciadas.

Uma coisa e outra obrigam a interpelar o território: por que razão é que ele atrai ou repele; por que razão se geram ali, e não noutro sítio, dinâmicas ou défices? A interrogação sobre a genealogia é mais forte e exige uma resposta mais profunda do que a interrogação sobre a mobilidade. A razão consiste nisto: a esta última basta considerar o território como espaço, isto é, suporte de localizações, local de recepção, enquanto a primeira atribui ao território - ele próprio - um papel activo, uma acção interveniente nos processos que se pretendem analisar. Esta última preocupação situa-nos já num campo radicalmente novo. Exige uma epistemologia do território.

Também defendi noutro contexto que a relação entre 'mobilidades' e 'territorializações' (Reis, 2001) é uma das tensões que estabelecem a organização social. Para quem dedica atenção às espacialidades do desenvolvimento, esta proposta, num primeiro passo, não contém em si mesma nenhuma novidade. É facilmente aceite que os dois lados da formulação são elementos presentes no funcionamento dos territórios. Mas pode já não ser assim quando se interpreta a lógica da relação entre ambos os termos e, sobretudo, o que daí resulta. O problema é, então, simples: ou as territorialidades são meras formas de reprodução das mobilidades e das capacidades de dominação dos fatores móveis, ou existe entre ambas uma tensão que obriga a equacionar o que confere força e poder a 
ambos os lados. Esta última possibilidade tem que interpretar o território de um ponto de vista que inclua o poder que ele incorpora, as inter-relações e os atores que o formam, as iniciativas que ele gera e as transformações a que ele obriga. O problema não muda quando se consideram as 'hiper-mobilidades' (Damette, 1980; Hudson, 2004).

Sucede que a perspectiva territorialista tem na sua génese e na sua natureza o pressuposto de que a arbitragem entre mobilidades (ou fluxos) e territorializações não é uma simples procura de um equilíbrio formal entre as duas fontes de influência. Se assim fosse, tornava-se legítimo perguntar qual era a sua utilidade e a sua razão de ser. Tratar-se-ia seguramente de um exercício de bom senso, mas ele seria relativamente anódino e apenas formalmente relevante. Seria um resultado de soma nula. Não representaria um acréscimo epistemológico. Tratar-se-ia de pouco mais do que de uma delimitação de terreno, pois serviria sobretudo para definir o campo de trabalho de um grupo de especialistas, que assim estabeleceria e defenderia a sua 'profissão'. Teríamos apenas mais um termo - território - no cardápio dos recursos discursivos e instrumentais das ciências sociais.

Neste sentido, o território deve passar de utensílio descritivo para conceito que estrutura e diferencia a perspetiva interpretativa em que se inclui - e com isso se junta a um enorme conjunto de outras discussões no campo da epistemologia e da metodologia das ciências sociais. Isto implica que se atribua à proximidade - e aos comportamentos relacionais e às práticas cognitivas que ela desencadeia - um papel ontológico, e não apenas uma utilidade descritiva, um lugar na determinação dos processos sociais de natureza idêntica (a qual não significa necessariamente o mesmo peso em todas as circunstâncias) ao de outros determinantes sociais. Implica também que se concebam as dinâmicas socioeconómicas globais como algo que não está organicamente estabelecido. As hierarquias não estão pré-definidas e não têm de ser previsíveis. Pelo contrário, os territórios tornam-se elementos da genealogia dos processos, conferindo-lhes uma natureza incerta, contingente e inesperada. O pressuposto funcionalista que antecede muitas das análises sobre a evolução dos fenómenos sociais deve recuar, em nome de uma pergunta verdadeiramente inicial sobre a sua genealogia. E, consequentemente, deve passar de uma visão organicista das estruturas sociais para uma noção que reconheça o seu polimorfismo.

Colocar o território num contexto epistemológico como este é reificação do território? Parece-me que não, pois o que está aqui em causa não é o território enquanto conjunto físico de paisagens materiais, mas o território enquanto expressão e produto das interações que os atores protagonizam. O território, nestas circunstâncias, é proximidade, atores, interações. E é também um elemento crucial da matriz de relações que define a morfologia do poder nas sociedades contemporâneas.

Assim sendo, não me parecem satisfatórias as propostas que sugerem que uma boa apreciação dos fenómenos sociais exige um simples equilíbrio formal entre as variáveis em presença. Interpreto assim a proposta de Ray Hudson (2004), quando trata do entendimento das espacialidades que constituem as economias e as sociedades. Situando-se perante o mesmo problema que formulei acima e a que chamei tensão entre mobi- 
lidades e territorializações, Hudson fala de fixities of spaces e de fluidities of circuits and flows. Contra as posições que defendem que o elemento-chave para compreender as sociedades contemporâneas está num destes elementos (sendo o outro necessariamente subsidiário), a sua proposta é towards a conceptualization in terms of the relations between circuits, flows and spaces (Hudson, 2004: 99). Uns e outros são complementares, mais do que concorrentes.

Há muito que sabemos que o território não é apenas o espaço físico. $\mathrm{O}$ território para que olham os economistas, os sociólogos, os planeadores é um território relacional. A ideia de que, nas sociedades contemporâneas, os territórios são matrizes quer sublinhar esta sua permanente condição relacional. A afirmação da natureza matricial do território exige, em primeiro lugar, a afirmação da sua relevância enquanto ordem material e socioeconómica: as cidades e os sistemas urbanos são realidades materiais e não apenas construções concetuais; os recursos e os activos de uma região, assim como as mobilidades pendulares que mapeiam o seu sistema de emprego são identificáveis e geram economias locais diferenciadas.

A resposta à pergunta "o que é um território?" exige que consideremos três dimensões das estruturas e das dinâmicas territoriais: (a) proximidade, (b) densidade e (c) polimorfismo estrutural.

A proximidade é o contexto e as relações que ela propicia: são pessoas em co-presença; são ordens relacionais; são consolidações de culturas práticas e de instituições; é conhecimento e é identidade partilhada de forma colectiva. É este conjunto de circunstâncias que desencadeia a formação de densidades.

As densidades exprimem-se em interações continuadas, em aprendizagens e competências (externalidades cognitivas) que coordenam a ação de atores sociais, em multiplicação ou definhamento de contextos institucionais e de governação.

O polimorfismo estrutural assinala o facto de a tensão entre mobilidades e territorializações - isto é, o exercício matricial de que os territórios são parte - produzir diferenciações dentro de ordens mais vastas. Quer dizer, o mundo não é representável por uma organicidade sistémica em que tudo-é-explicado-por-tudo, como acontece, por exemplo com a estrita lógica centro-periferia, ou pelas visões globalistas que dela são tributárias. O mundo é melhor representado pela ideia de polimorfismo, isto é, por uma visão das coisas em que há espaços estruturais de iniciativa e de autonomia, cujo desenvolvimento afirma a sua relevância própria e exerce efeitos de feed-back sobre outros espaços. Nisto consiste a noção de que a incerteza e as trajetórias inesperadas são também parte do mundo.

Argumento, pois, que há justificação de sobra para entender o território como detentor de um papel e de um significado próprios, não apenas complementares e muito menos derivados de determinações com as quais estabeleça uma relação hierárquica dependente ou sucessiva.

Das três dimensões que acabo de propor, duas - proximidade e densidade - formam a rede matricial interna dos territórios: representam a identidade, a copresença e a capacidade dinâmica, assim como o conflito, a ausência, as tendências regressivas. A terceira 
dimensão - polimorfismo estrutural - representa essencialmente as relações de poder em que os territórios participam (e que podem ser positivas ou negativas, promocionais ou degradativas) e o modo como esses territórios se inscrevem no mapa estrutural do mundo (como margens ou como centros; como lugares ascendentes e transformadores da matriz global ou como lugares descendentes).

Nas discussões que hoje estão em cima da mesa sobressaem duas críticas principais às perspetivas territorialistas: o poder e a política (as relações de poder desiguais, o conflito) têm sido descartados do discurso e do quadro interpretativo que aquelas produzem, em favor da ênfase que é dada à região enquanto lugar comum e, muitas vezes, espaço auto-suficiente. Negligencia-se assim a existência de um processo de desenvolvimento desigual gerido por agentes de governação exteriores e com poder estabelecido, pensando que a ação cooperativa localizada é suficiente para fundar e estruturar as evoluções locais (produtivas, de inovação, de aprendizagem).

Niel Brenner (2003: 304) é muito veemente quando interpreta a emergência da escala metropolitana e da sua governação na agenda da organização territorial europeia como um processo essencialmente crisis-induced, derivado da transformação da espacialidade do Estado (um processo de state rescaling) e como a politically mediated outcome of complex, cross-national forms of policy transfer and ideological diffusion. Por isso mesmo, nas transformações territoriais que observamos, regions have become major geographical arenas for a wide range of institutional changes, regulatory experiments and political struggles within contemporary capitalism.

Segundo esta visão das coisas, o problema consiste em saber de que forma social relations, operating across different geographical scales, interact in the reproduction of the political and economic landscape through time. Neste sentido, as regional institutions são key institutional channels through which wider regulatory practices are interpreted and ultimately delivered (Cumbers et al., 2003: 335, sublinhado meu).

Nesta linha de pensamento, um programa de investigação suficiente seria o que se concentrasse nas conexões entre os wider regulatory mechanisms and specific social and political interests within regions (ibid., idem). Os territorialistas seriam, assim, simples especialistas da micro e meso reprodução do macroglobal no território. Aliás, a esta luz, a materialidade do território - e, portanto, o seu significado ontológico - não faria sentido, pois ela é amplamente superada por um outro processo, o da "produção social das escalas". As regiões não são elas próprias, mas antes "open spaces", entidades úteis para a promoção da inovação e da aprendizagem na economia global, que é quem as molda e lhes define as possibilidades. Esta ideia de que há relações que precedem e anulam a materialidade territorial, sendo esta última caracterizada por um elevado grau de volatilidade, no quadro de "espaços abertos", deixa de lado qualquer possibilidade de entendermos a morfologia, não só do poder, mas também das próprias realidades socioeconómicas.

A noção de reprodução e a visão de certos fenómenos e entidades como canais são consequências coerentes com o realismo crítico (Sayer, 1992), que é a posição filosófica em que as perspectivas que tenho estado a referir se apoiam. 
The crux of the realist position is the ontological claim that there is an independent reality, made up of social objects and structures, although, crucially, our knowledge and understanding of this is always partial and provisional, being channeled through discourse and representation (Cumbers et al., 2003: 334)

Neste quadro, os territórios não seriam parte daquela "realidade independente", estariam fora dela e, por isso, seriam essencialmente representações sociais, construções discursivas. Quer dizer, a influência do realismo crítico é superada por uma agenda que atribui dignidade ontológica a entidades como o poder, o Estado, a racionalidade dos agentes dotados de mobilidade, mas não aos territórios. Ora, the idea that territorial differentiation within the modern state had been entirely eliminated was always an exaggeration (Keating, 2014: 240)

A questão central a que as perspectivas territorialistas têm de responder é a que tem a ver com a relação entre o que define um território - interacções de proximidade, contextos de co-presença - e as suas relações heterónimas. É aí que a questão do poder e das relações desiguais essencialmente se coloca. Não basta postular estas duas dimensões, nem basta colocá-las lado a lado. O desafio é deduzir as resultantes das suas inter-relações: "não se trata de postular o local (...) mas de deduzi-lo" (Benko e Pecqueur, 2001: 39). Para isso, é útil a rejeição dos postulados da convergência (só há one single best way), da hierarquia funcional utilitária (os lugares só existem numa hierarquia porque são úteis ao seu vértice) e do entendimento de que os sistemas colectivos se "fecham" apenas através de um único princípio de racionalidade e regulação. A outro propósito, Charles Sabel (2004: 4) escreveu sobre "disruptive technology" para indicar que esta é a superior alternative to the currently dominant know how, whose potential escapes the most masterful producers and users of the dominant method precisely because their experience teaches how to improve on what they already know; disruptive technologies therefore begin to realize their potential in secondary or peripheral markets.

\section{PARA CHEGAR ÀS POLÍTICAS: A QUESTÃO “INICIAL” E A RAZÃO DE SER}

O que se diz acima acerca do território é, evidentemente, a base para ensaiarmos as políticas que lhe dizem respeito. Para pensarmos as políticas, o território tem, pois, que ser interpretado na sua ossatura e na sua diferenciação. Sabemos que ele é distância e que ele é proximidade. O território-distância é aquele sobre o qual se desenvolvem atividades e se interligam pontos. O território-proximidade é o que aglomera e proporciona a coordenação dos atores que nele agem e que, afinal, o constituem. Usarei, por isso, a proximidade como o principal dos critérios para apontar quais podem ser as políticas do território.

Já se sabe que as sociedades, as nações, as comunidades, a economia, a vida individual, as empresas se desenvolvem num espaço, assentam em territórios, não são pontos sem dimensão. Não há, por definição, países sem espaço. As sociedades são por natureza, entidades espaciais. A primeira razão pela qual os territórios confrontam necessaria- 
mente as políticas públicas é, portanto, uma razão "natural", "constituinte". Tomar em conta o território deveria ser, pois, uma simples questão de administração, à maneira das que motivaram a formação inicial das nações ou qualquer outra forma de ocupação territorial e que, por exemplo, levaram os poderes em busca de soberania a criar cidades de fronteira, a construir castelos ou a estabelecer a justiça e formas locais de a administrar. E não é por um território já estar constituído que ele deixa de ser a base do exercício do poder e da organização, assim como do funcionamento orgânico das comunidades. Por isso mesmo, também as sociedades contemporâneas tomam decisões que decorrem, porventura, da mesma necessidade de pressupor o território que correspondeu àquelas deliberações mais ancestrais. Por exemplo, conectar os pontos nucleares de um espaço organizado através de infra-estruturas que possibilitem uma mobilidade adequada e garantam a presença, pelo menos potencial, em todas as partes que constituem um espaço é, evidentemente, uma indicação da existência estrutural e incontornável do território. Assim sendo, a questão da inclusão do território nas políticas não deveria ser um problema ou mesmo um "assunto". Não deveria ser preciso estar sempre a regressar ao início do mundo. Mas é. Há um eterno problema de conceção territorial das políticas. Porquê?

$\mathrm{O}$ argumento anterior inclui uma questão que também deve ser dilucidada: esta presença do território nas ações que organizam o espaço é para que sobre ele incida um poder e uma relação de heteronomia, ou para que cada território seja composto, ele próprio, pelas mesmas condições e pelos mesmos valores que definem o conjunto, e na ausência dos quais estaríamos perante uma óbvia demonstração de fragmentação? É para que o território seja objeto ou sujeito? Coletar impostos, sujeitar populações a um soberano ou distribuir "juízes de fora" foram formas de considerar a existência de territórios dentro de um espaço em construção. Mas foram essencialmente relações de domínio. Já a constituição de poderes locais, ainda que instituídos por forais, poderá ter sido uma maneira de assumir os territórios na sua condição de parte própria de um coletivo.

Por que razão, em síntese, é que há políticas territoriais? Porque há um Estado local, fruto da evolução democrática, e há atores políticos locais que o exigem? A existência de um Estado local é, ela mesma, a condição para que existam políticas do território ou elas existiriam sem ele? Ou existem políticas territoriais porque, sendo as sociedades entidades territoriais, se deve promover a justiça espacial? Mas, nesse caso, elas deverão ser encaradas como simples políticas redistributivas, uma espécie de alocação top-down de recursos? Ou o pressuposto de que a riqueza não está bem distribuída é essencial e as políticas territoriais têm de existir para que o processo de criação de riqueza seja, na sua origem e na sua natureza, tão robusto que inclua ele próprio, à partida, a justiça espacial, na medida em que de modo equilibrado valorize todos os recursos territorialmente disponíveis? A resposta mais adequada a dar é, defende-se aqui, a que torne as políticas do território num elemento básico da deliberação pública e não um suplemento mais ou menos forçado.

Esta relação necessária das deliberações políticas com o território, em vista da circunstância "natural" de as sociedades serem entidades territoriais, assim como a presença conflitual e muitas vezes dificilmente dilucidável da condição de objeto ou de sujeito, clarifica pelo menos uma coisa: as políticas, tendencialmente todas as políticas, têm incidências 
territoriais. As diferentes evoluções do ordenamento espacial exprimem sempre o "movimento" do território, seja ele positivo ou negativo, reactivo ou endógeno. Por esta razão, a solução dicotómica de distinguir, por exemplo, políticas sectoriais de políticas territoriais merece ser discutida. Desde logo porque é frequente estabelecer-se uma espécie de relação subsidiária das segundas em relação às primeiras, da qual resulta que estas seriam as verdadeiras deliberações, enquanto aquelas seriam compensações ou formas de mitigação. Isto acontece, por exemplo, no modo como se entende o papel a desempenhar por certas políticas (ambientais ou "territoriais") relativamente à influência, supostamente negativa, de políticas sectoriais específicas (como as de transportes ou as agrícolas) sobre as dinâmicas territoriais, devendo então convocar-se, para minorar as consequências, políticas de ordenamento do território, de desenvolvimento regional ou de conservação da natureza. A finalidade das políticas territoriais e ambientais seria então "gerir os efeitos desencadeados por políticas sectoriais”. Ora, na verdade, esta distinção não é aceitável, se nos colocarmos numa posição que pretenda discutir as questões a partir de uma base territorialista.

O ideal seria que se assumisse, tendo em conta o nosso pressuposto inicial, que dificilmente se pode admitir a noção de que há políticas territoriais e políticas não-territoriais. É verdade que há diferentes sensibilidades das políticas ao território, mas todas deveriam ser, enfim, territoriais. Admitamos que a política diplomática e de relações externas, assim como a de defesa, são, salvo casos específicos ou extremos, de incidência não-territorial. Mas já não é possível dizer-se, nos dias que correm, que a de justiçą ou da segurança (que compõe com a restante, as chamadas funções de soberania) cabem nesse conjunto. Isto remete-nos, aliás, para a ideia de que a estrutura essencial do Estado e da administração, independentemente das funções de que estejamos a falar, é intrinsecamente territorializada e tem, portanto, necessárias incidências territoriais. Há evidentemente deliberações que, podendo estar para lá de cada território e podendo considerar-se "sectoriais", têm óbvia incidência territorial. O exemplo mais imediato é o das grandes infraestruturas de transporte ou da energia. Não é apenas porque elas ocupam e transformam o uso do território. É porque eles comportam lógicas de acesso e de ordenamento, no primeiro caso, e de alteração da hierarquia do uso de recursos, no segundo.

\section{AS POLÍTICAS DO TERRITÓRIO}

A classificação das políticas do território que vou propor assenta em quatro categorias principais, a que acrescento uma quinta, de natureza geral. Encontrei razões para autonomizar um conjunto de políticas a partir da sua natureza territorial e definir aquilo que contribui para tal qualificação. Mas defendo que, na verdade, a distinção entre estas políticas e outras que se poderiam considerar como não-territoriais deveria ter escassa justificação e, para além de certas condições, até se pode ter por indesejável. De facto, sendo as comunidades humanas entidades territoriais, poucas hão-de ser as políticas que não são do território. E não teríamos de chegar a esta conclusão apenas pelas incidências espaciais que todas as políticas têm, mas pela sua conceção inicial. 
A apresentação de uma taxonomia elementar de políticas do território, para além do que este objetivo representa em si mesmo, dá também lugar a uma visão pluralista sobre a forma de organização das economias e das sociedades. Com efeito, em vez da ideia de que os capitalismos se organizam apenas através da coordenação pelo mercado, é mais razoável supor que há vários mecanismos para atingir esse fim e que é daí que resulta a organização socioeconómica: há mercado, há Estado, há empresas e hierarquias empresariais, há associações e há comunidades e há, em concreto, comunidades territoriaisii. E é de tudo isto que resultam as deliberações e os comportamentos individuais, assim como as dinâmicas coletivas.

\section{Uma definição: as condições da territorialidade de uma política}

Refiram-se então as condições que devem ser tomadas em conta para se considerar a territorialidade de uma política. Podemos considerar que as políticas do território são aquelas em que a coordenação entre atores se faz predominantemente pelo território e não por quaisquer outros mecanismos. Courlet (2008: 46) distingue três tipos de coordenação: a que se faz pelo mercado, a que corresponde a uma ordem hierárquica - seja pública, seja dentro de uma grande empresa - e a territorial, resultante de interdependências entre agentes ou entre agentes e instituições, que originam dinâmicas específicas. É na medida em que, na sua origem e nas suas finalidades, estabeleçam laços entre atores locais, estruturem e capacitem o território, desenvolvam o capital social e dêem coerência a políticas tidas por setoriais que há políticas que assumem a qualidade de territoriais. Não deviam ser assim todas as políticas, na medida em que sejam políticas de desenvolvimento? Deviam, certamente. A própria abordagem horizontal não devia ser exclusiva de algumas políticas, então ditas territoriais, antes devendo ser matéria presente em qualquer metodologia de formulação e concretização de políticas.

Em todo o caso, admita-se que políticas territoriais são, tendo em conta a definição proposta, as que, no plano global em que se inserem (regional, nacional, europeu), promovem o policentrismo, intervêm na organização dos meios territoriais a que se dirigem, assentam em redes de proximidade e consolidam institucionalmente as diferentes componentes espaciais de um todo.

Estas três condições são, por assim dizer, condições da territorialidade de uma política. Se a lógica policêntrica (seja qual for a escala de intervenção) é posta em causa, pode estar a desfazer-se o que é mais intrinsecamente territorial numa política: a relação com um espaço estruturado, relacional, polimórfico. Se a condição de organização dos meios se perder, dificilmente é a política constituinte do território que recuará para a mera condição de espaço anódino de recepção de inputs externos. Se uma política não pressupuser e não tiver como finalidade densificar relações dentro do território a que se destina, valorizando a proximidade, será certamente uma política no território mas não do território. A condição final, a definição da natureza territorial de uma política, deve observar-se no plano institucional. Não apenas das instituições formais (políticas, jurídicas...) mas também das instituições materiais, aquelas que revelam a capacidade organizacional, 
o desenvolvimento de vínculos substantivos entre as pessoas e as estruturas da economia e da sociedade: sistema de emprego, formação e qualificações, escola, actividades em que predominem as formas de learning by doing, por exemplo.

\section{Uma taxonomia}

Uma taxonomia de políticas do território é sempre redutora. É-o especialmente se tivermos em conta o que já se discutiu sobre a necessária consciência e inteligência territorial de quase todas as políticas. No entanto, o compromisso com a definição anteriormente proposta autoriza um exercício classificatório como o que se segue, através de quatro categorias e de uma adicional.

\section{a) A política de ordenamento e infra-estruturação}

O território apresenta-se, por natureza, em várias escalas. Há, em cada escala, macro territórios, isto é, os territórios que contêm territórios. A definição do quadro trans-escalar com que se concebe o território é, porventura, o nível mais amplo de construção de políticas: são políticas de ordenamento que se constituem através dos quadros concetuais que se estabelecem, dos espaços de deliberação que se instituem e da infra-estruturação que promovem. A política de ordenamento e estruturação do conjunto composto por todos os territórios inclui, por isso, o quadro de programação por que se opta, assim como a política de desenho da rede de equipamentos e de infra-estruturas e as relações de mobilidade e os transportes. É neste âmbito que ganha todo o sentido a ideia de promoção do policentrismo e dos princípios da descentralização que são próprias da lógica territorial.

Pode dizer-se que não apenas se tornou consensual que a gestão e o ordenamento do território constitui um problema relevante da sociedade, como também que há justificações de sobra para a convicção de que essa é a forma de dedicar atenção ao território entendido como recurso e como um contributo para a solução de certos défices persistentes nas nossas sociedades. É, por isso, que é essencial consolidar uma visão do território e identificar os espaços pertinentes de racionalidade das políticas públicas. Cremos poder defender que há hoje em Portugal um consenso suficiente acerca do modo como se podem identificar esses espaços, isto é, como constituir uma escala sub-regional apropriada a um correto entendimento das relações entre desenvolvimento e território. Mas não é claro que esse consenso resulte em políticas coerentes.

O PNPOT - Programa Nacional da Política de Ordenamento do Território - foi um exercício de definição, de um ponto de vista substantivo, desses grandes espaços pertinentes. Procurou-se, de facto, identificar a ossatura territorial existente. Fez-se isso, por exemplo, através dos grandes sistemas urbanos consolidados, ou dos que representassem novos dinamismos territoriais, assim como dos espaços de baixa densidade, ou dos territórios de "fronteira", quer na aceção territorial do termo, quer para significar que são "fronteiras" de desenvolvimento. 


\section{b) A política urbana}

A política urbana é, tem de ser, uma panóplia de várias políticas. No quadro de qualquer discussão, e muito particularmente na que estamos a propor, só pode ser encarada de forma global e integrada. É isso que decorre do princípio da coordenação pelo território. Se isto é verdade para qualquer meio territorial, é-o de forma particularmente intensa para os meios urbanos. Na verdade, as cidades, os conjuntos urbanos, as metrópoles, são casos de particular intensidade territorial. São ainda representações singulares da forte convergência entre políticas de intervenção física (no desenho territorial, no edificado, nas relações de mobilidade) e ações de natureza relacional, como as que dizem respeito à qualificação das pessoas, à inclusão social, à promoção de atividades ou à capacitação institucional. Na verdade, para além do óbvio significado territorial, material e de dimensão, um meio urbano ou metropolitano é essencialmente relevante pelo seu poder institucional e pela sua posição relacional face a outros espaços, sejam eles de poderio maior ou equivalente, sejam menores. A política urbana combina assim de forma particularmente intensa aspetos físicos (concentrando intervenções complexas que dificilmente se podem encontrar noutros lugares), processos imateriais de incidência local e formas institucionais e relacionais com contextos externos. Os meios urbanos têm ainda a singularidade adicional de combinarem tempos históricos muito distintos e sobrepostos. A coalescência de diferentes temporalidades nas capacidades contemporâneas de uma cidade é, porventura, a sua marca mais distinta.

No conjunto, as cidades e as intervenções políticas de natureza territorial que elas e os meios metropolitanos suscitam resultam de uma circunstância absolutamente central na análise territorial: a presença de aglomerações e a gestão da proximidade. O mais poderoso exemplo de uma economia de proximidade é, evidentemente, uma grande metrópole. Através da forma como a condição urbana se consolida no território revela-se a espessura e a estrutura do próprio território. As cidades ou, numa aceção mais ampla, os sistemas urbanos ${ }^{\text {iii }}$ são, de facto, uma forma lapidar de constituição do território, e isso tem sido demonstrado para Portugal em muitos estudos que, simultaneamente, tipificam as principais estruturas urbanas do nosso país. Já se sabe que a urbanização é um fenómeno marcante das sociedades contemporâneas porque a ele estão ligados muitos dos factores que influenciam a geração das mais relevantes dinâmicas: comunicação, cultura, poder, aprendizagem e conhecimento, inovação ou consumo. As cidades e os sistemas urbanos são, através das economias de aglomeração em que assentam e que geram, a grande ossatura do território. Pela co-presença ativa e pela proximidade são espaços de dinamismo e de mudança.

Numa sociedade como a portuguesa estas questões são particularmente relevantes. Por um conjunto de razões. Em primeiro lugar, porque as áreas dinâmicas da economia são mapeadas pelas principais estruturas urbanas - a "região metropolitana de Lisboa" e a "aglomeração metropolitana do Norte litoral", bem assim como o "polígono urbano do Centro do país ou a aglomeração algarvia" - e aqui residem muitos dos fatores específicos de qualificação e diferenciação positiva, designadamente os que resultam do 
conhecimento, da criatividade, da conectividade e, em geral, dos recursos imateriais. A cidade é, pois, um meio especialmente qualificado. Em segundo lugar, os espaços urbanos são relevantes porque o bem-estar das pessoas, designadamente quando lhes está associada uma economia de serviços e o acesso a equipamentos é, em muitos aspectos decisivos, beneficiário da proximidade à cidade e às funções urbanas. Em terceiro lugar, a cidade e a organização urbana são elementos críticos de ordenamento do território, de coerência da rede de equipamentos e de infra-estruturas, de comunicações e mobilidade, de capacidade logística. Finalmente, porque a própria articulação dos diferentes espaços do país - designadamente a articulação do interior - tem nos meios urbanos um instrumento principal.

É bem sabido que o meio urbano, em Portugal, carece de organização, de qualificação e de articulação e que há problemas de exclusão graves relativamente ao que deveria definir a própria cidade, nos termos acabados de referir. Os problemas urbanos são, pois, importantes tanto pelo défice como pelo excesso. Pelo défice, porque há problemas ambientais por resolver, há problemas de qualidade do meio construído e do espaço público, há problemas sociais, há uma lógica local que perdura, não deixando tratar muitos dos problemas à escala intermunicipal exigida pelo facto de os sistemas urbanos que formam o território serem aglomerações de vários municípios ligados pela proximidade. Pelo excesso, porque há problemas de congestão, de redundância na conceção das estruturas urbanas devido à falta de conceção de cada sistema urbano como um todo, há problemas de sustentabilidade de equipamentos e de infra-estruturas, há articulações que é necessário promover.

\section{c) A política para a baixa densidade}

As duas condições apontadas anteriormente para compreender as políticas urbanas - aglomerações e proximidade - conduzem-nos, na mesma lógica, à que deve ser uma outra grande categoria de políticas do território: a que se dirige aos espaços de baixa densidade, aqui entendida não apenas como baixa densidade demográfica mas essencialmente como rarefação socioeconómica. A ideia de que há uma finalidade de gestão da proximidade mantém-se, evidentemente. Mas agora encontramos o simétrico da aglomeração. Mas nem por isso é menos território o que se qualifique como território de baixa densidade. Ele deve ser na mesma sujeito de políticas e elemento de coordenação de atores. Claro está que a estas políticas presidem fins próprios: estruturação territorial, organização e valorização de recursos específicos, definição de condições de bem-estar e acesso a padrões gerais de sociabilidade, qualificação institucional.

Os espaços de baixa densidade, tal como foram definidos anteriormente, constituem a mais ampla fatia do território nacional mas representam menos de $1 / 4$ da população do país. São constituídos por espaços urbanos de pequena dimensão, sem proximidade física e socioeconómica com outros espaços urbanos (pensa-se nas sedes de concelho não integradas em sistemas urbanos plurimunicipais), e por espaços não-urbanos de características rurais profundas ou tributários dos anteriores. A sua importância para a organização 
do país mede-se por dois indicadores: o papel que desempenham na ocupação e articulação do território (coesão territorial) e o modo como se constituem em lugares de vida de uma parte da população portuguesa (coesão social). É justamente na medida em que estes espaços são espaços de articulação do conjunto do território e lugares onde tem de ser garantido o acesso dos cidadãos que aí residem a serviços de natureza universal que eles são relevantes para as políticas públicas. As políticas que se lhes dirigem têm reconhecido estes aspetos e dão lugar especial à natureza dos recursos (endógenos) que as caraterizam e diferenciam.

\section{d) A política para os sistemas produtivos localizados}

O território manifesta-se também através da economia, isto é, através de especializações produtivas assentes em economias de proximidade e através da localização de recursos produtivos relevantes, de matérias-primas, de força de trabalho ou de conhecimento. De facto, as relações entre território e economia supõem uma opção activa e voluntarista pela estruturação da nossa economia à volta de sistemas produtivos localizados, entendidos como redes polares de qualificação das actividades em que a especialização regional pode ser desenvolvida. São sistemas diferenciados, que atendem à natureza estrutural de cada região, aos seus factores de competitividade específicos e à capacidade institucional instalada.

A condição para que a economia e a sua especialização produtiva possa superar a sua natureza frequentemente limitada e tecnicamente balizada ("segmental" e fragmentária), às quais é difícil atribuir impactos globais e efeitos de arrastamento cruciais no conjunto da economia, é, porventura, a sua valorização no quadro de sistemas regionais concebidos de forma articulada, propiciadores de condições competitivas horizontais e estimuladores da criação de plataformas organizativas comuns a várias atividades. Este parece ser um bom caminho para a geração de dinâmicas de nível superior. Ora, esta é uma tarefa que obriga a dar muita atenção à organização, às economias de eficiência colectiva.

Um pressuposto forte é que a inovação, sob as suas diferentes formas, pode ser altamente influenciada pelo território. Na sequência da influência de Alfred Marshall, os economistas usam a noção de economias externas. De facto, este economista identificou, no início do século XX, três grandes forças de aglomeração espacial da atividade produtiva: um mercado do trabalho localizado dispondo de mão-de-obra numerosa e qualificada (mercado do trabalho regional); uma oferta local e regional de bens intermédios e serviços especializados (por extensão, oferta de bens e serviços de produção, em geral); uma maior facilidade de circulação da informação a curta distância. Cada um destes três fatores é susceptível de proporcionar externalidades positivas aos produtores, funcionando como força indutora de atividade económica no local/região.

De modo geral, quer a criação de conhecimento (Vale, 2011), quer a absorção por uma empresa de conhecimento externo (difusão), requerem recursos humanos altamente qualificados. Está demonstrado que a existência de infra-estruturas científicas e 
tecnológicas numa região, isto é, a curta distância, é indutora de inovação ao nível da empresa por estas duas últimas vias. A manifestação mais expressiva desta influência do território na inovação encontra-se no fenómeno dos clusters, ou seja, dos grupos de agentes económicos (empresas, instituições de I\&D, entidades de interface) fortemente interligados, numa base local e regional, por fluxos de inovação ou atividade conjunta realizada neste domínio.

A proximidade facilita a circulação do conhecimento. Esta influência, para além de poder realizar-se através da partilha de conhecimento produzido em conjunto (pelo processo já descrito a propósito da primeira força de aglomeração de Marshall), manifesta-se ainda através da transferência de conhecimento já existente. É particularmente relevante, neste último caso, a circulação do conhecimento tácito, pois este carece de contactos presenciais e extravasa de uns agentes para outros, não só pela via dos mecanismos do mercado, mas também, em parte, através de canais exteriores ao próprio mercado. A sua transferência realiza-se, nomeadamente, sob a forma de cooperação informal.

Um sistema regional de inovação é caracterizável do seguinte modo: no vértice estão as atividades de investigação e desenvolvimento do sistema de ensino superior e dos centros tecnológicos, conjugadas com as parcerias e as estratégias de internacionalização que as empresas foram capazes de concretizar; a base é constituída por setores ou, numa aceção voluntarista, por clusters que são o resultado da acumulação de saberes e capacidades formados na sequência de já longos processos de especialização. $\mathrm{O}$ essencial do sistema de inovação não está, contudo, nem no seu vértice nem na sua base, considerados em si mesmos: o essencial está no desencadear de processos criativos, em relações emergentes que beneficiem das articulações entre o vértice e a base. Assim sendo, a "economia" dos territórios - a especialização que os caracteriza e os recursos que aí se aglomeram - deve ser retida como um elemento crucial da governação das políticas públicas.

\section{e) A política-política}

Há políticas que são qualificáveis como do território e este texto debruça-se sobre elas. Mas é também claro que há outra política que, na medida em que é o lugar das grandes deliberações que organizam a sociedade, não é em nada alheia ao território. É o que podemos chamar a política-política. Ou, noutra perspectiva, o quadro institucional que, tanto no plano formal, como nos da cultura e dos comportamentos coletivos, organiza e qualifica uma sociedade e a ordem relacional em que ela assenta. É aqui, evidentemente, que se fica a saber o que vale o território. Se ele é sujeito ou objeto. Se é uma restrição a que tem de se atender ou valor que serve para estabelecer interações ou finalidades.

É também neste quadro que, enfim, ficamos a saber se é preciso falar de políticas do território, forçando dicotomias indispensáveis, ou se se assume já que, afinal, todo o desenvolvimento é desenvolvimento territorial e, por isso, estamos já para além dessas dicotomias e estamos perante políticas que, ab initio, valorizam recursos e promovem a justiça, sem qualificativos. 


\section{CONCLUSÃO}

Há, pois, boas razões para dispormos de uma noção prática e útil de governação territorial. Algo que explicite o modo como os diversos níveis espaciais são integrados no modelo institucional de organização da decisão, como a articulação territorial das políticas - tanto as sectoriais como as territoriais - é alcançada e como o modelo de administração e gestão das políticas públicas se inscreve no território e o assume. Tudo, afinal, o que nos permita supor que todo o desenvolvimento é concebido como desenvolvimento territorial.

Trata-se, sem dúvida, de uma escolha adequada das escalas territoriais pertinentes para a macro-conceção de um quadro global de atuação. Mas trata-se também da relação a estabelecer entre cada medida de política e a escala territorial em que elas se planeiam, decidem e executam (o âmbito territorial de cada política) ou das esferas da administração estatal que se elegem como agentes ativos de conceção, gestão e decisão ou, ainda, da relação a estabelecer com os atores sócio-político-económicos, tanto públicos como não-públicos. Evidentemente que estas considerações resultam do pressuposto de que o território é um elemento da governação das políticas públicas. Isto supõe que é possível definir com clareza qual é a materialidade do território e de que modo é que ela é um fator de operacionalização daquelas políticas.

\section{BIBLIOGRAFIA}

Benko, G. \& Bernard, P. (2001). Os recursos de territórios e os territórios dos recursos. Geosul, 16 (32), 31-50.

Brenner, N. (2003). Metropolitan institutional reform and the rescaling of the State space in contemporary Western Europe. European Urban and Regional Studies, 10 (4), 279-324.

Courlet, C. (2008) L'Économie Territoriale. Grenoble: Presses Universitaires de Grenoble.

Cumbers, A., Danny, M., \& Robert, M. (2003). Institutions, power and space: assessing the limits to institutionalism in economic geography. European Urban and Regional Studies, 10 (4), 325-342.

Damette, F. (1980). The regional framework of monopoly exploitation. In C. John, H. Ray \& L. Jim (Eds.), Regions in Crisis: New perspectives in European Regional Theory (76-92). Londres: Croom Helm.

Hudson, R. (2004). Thinking through the geographies of the new Europe in the new millennium. European Urban and Regional Studies, 11 (2), 99-102.
Keating, M. (2014). Introduction: Rescaling Interests. Territory, Politics, Governance, 2-3, 239-248.

Reis, J. (2001). A Globalização como Metáfora da perplexidade: Os Processos Geo-económicos e o 'Simples' Funcionamento dos Sistemas Complexos. In B. S. Santos (org.), Globalização: Fatalidade ou Utopia? (109-134). Porto: Edições Afrontamento.

Reis, J. (2009). Ensaios de Economia Impura, Coimbra: Almedina.

Reis, J. (2013). O regresso ao princípio do mundo: uma visão territorialista de denúncia e contraposição. In M. M. Serrano \& P. Neto (coord.), Espaço: Perspetivas multidisciplinares sobre a construção dos territórios (29-39). Coimbra: Sílabo.

Sabel, C. (1998). Constitutional orders: Trust building and response to change. In J. R. Hollingsworth \& R. Boyer (Eds.), Contemporary capitalism: The embeddedness of institutions (155-181). Cambridge: Cambridge University Press.

Sabel, C. (2004). Districts on the move: Notes on the Tedis Survey of the internationalization of district firms", http://www2.law.columbia.edu/sabel/. 
Sayer, A. (1992). Method in Social Science. Londres e Nova Iorque: Routledge.

Vale, M. (2011). Innovation networks and local and regional development policy. In A. Pike,
A. Rodriguez-Pose, \& J. Tomaney (Eds.), A handbook of local and regional development (413-424). London: Routledge.

i Tem-se obviamente presente a questão do mapa judiciário na discussão nacional recente.

ii Para uma aproximação às várias formas institucionais de governação das economias veja-se Reis (2009).

iii Um sistema urbano é uma realidade territorial sub-regional com as seguintes características: uma aglomeração de pessoas, uma situação de proximidade (é o espaço-tempo que melhor serve de medida para a distância), uma economia de tipo urbano (estão nestes sistemas as universidades, os institutos politécnicos e as escolas secundárias; estão os hospitais; estão os principais serviços; estão os centros de consumo e de lazer; estão também as bacias de emprego secundário e terciário: e todas estas características se sobrepõem e articulam num mesmo espaço), uma situação caracterizada por relações intensas e pela mobilidade (dentro destes espaços, em distância curta, muitas pessoas deslocam-se e interagem diariamente). 